\title{
Fluvastatin Attenuates Diabetes-Induced Cardiac Sympathetic Neuropathy in Association With a Decrease in Oxidative Stress
}

\author{
Akira Matsuki, MD; Takashi Nozawa, MD; Norio Igarashi, MD; Mitsuo Sobajima, MD; \\ Takashi Ohori, MD; Takayuki Suzuki, MD; Nozomu Fujii, MD; \\ Akihiko Igawa, MD; Hiroshi Inoue, MD
}

\begin{abstract}
Background: Increased oxidative stress might contribute to diabetic (DM) neuropathy, so the effects of longterm treatment with fluvastatin (FL) on myocardial oxidative stress and cardiac sympathetic neural function were investigated in diabetic rats.

Methods and Results: FL (10 mg $\mathrm{kg}^{-1} \cdot$ day $^{-1}$, DM-FL) or vehicle (DM-VE) was orally administered for 2 weeks to streptozotocin-induced DM rats. Cardiac oxidative stress was determined by myocardial 8-iso-prostaglandin $\mathrm{F}_{2 \alpha}$ $\left(\mathrm{PGF}_{2 \alpha}\right)$ and NADPH oxidase subunit 222 $^{\text {phox }}$ mRNA expression. Sympathetic neural function was quantified by autoradiography using ${ }^{131} \mathrm{I}$ - and ${ }^{125}$-metaiodobenzylguanidine (MIBG). FL did not affect plasma glucose levels but remarkably decreased $\mathrm{PGF}_{2 \alpha}$ levels compared with DM-VE rats $(13.8 \pm 9.2$ vs $175.0 \pm 93.9 \mathrm{ng} / \mathrm{g}$ tissue), although $\mathrm{PGF}_{2 \alpha}$ levels were below the detection limit in non-DM rats. FL significantly reduced myocardial p22 ${ }^{\text {phox }} \mathrm{mRNA}$ expression. Cardiac ${ }^{131}$ I-MIBG uptake was lower in DM-VE rats than in non-DM rats, but the decrease was attenuated in DM-FL rats $(1.31 \pm 0.08,1.88 \pm 0.22$, and $1.58 \pm 0.18 \% \mathrm{~kg}$ dose/g, respectively, $\mathrm{P}<0.01)$. Cardiac MIBG clearance was not affected by the induction of DM or by FL, indicating that the reduced MIBG uptake in DM rats might result from impaired neural function.
\end{abstract}

Conclusions: FL ameliorates cardiac sympathetic neural dysfunction in DM rats in association with attenuation of increased myocardial oxidative stress. (Circ J 2010; 74: 468-475)

Key Words: Metaiodobenzylguanidine; Prostaglandin $\mathrm{F}_{2 \alpha}$; Radioisotope; Statins

A utonomic neuropathy is a major complication of diabetes mellitus (DM) and is associated with high morbidity and mortality. ${ }^{1-3}$ Cardiac sympathetic neural dysfunction in diabetic patients can be identified using ${ }^{123}$ I-metaiodobenzylguanidine (MIBG) or ${ }^{11} \mathrm{C}$-hydroxyephedrine $^{4-7}$ as radiotracers. The etiology of diabetes-induced cardiac sympathetic neural dysfunction remains unclear, but increased oxidative stress might be involved in its pathogenesis. ${ }^{89}$ Hyperglycemia induces oxidative stress via increased activity of the polyol pathway, ${ }^{10}$ nonenzymatic glucose oxidation yielding advanced glycation end-products, ${ }^{11}$ protein kinase $\mathrm{C}$ activation ${ }^{12}$ and superoxide overproduction via the mitochondrial electron transfer chain. ${ }^{13}$ However, whether diabetic neuropathy of the heart is associated with increased cardiac oxidative stress and whether a reduction in cardiac oxidative stress could attenuate neural dysfunction remain to be elucidated.

Three-hydroxy-3-methylglutaryl coenzyme A (HMG-CoA) reductase inhibitors, also known as statins, might favorably affect mortality and morbidity among diabetic patients, inde- pendently of their cholesterol-lowering effects, ${ }^{14,15}$ attributable to a reduction of oxidative stress and improving endothelial dysfunction. ${ }^{16,17}$ Experimental animal and clinical studies ${ }^{18-20}$ have revealed a favorable effect of statins on diabetic peripheral neuropathy. Ii et al found that rosuvastatin restores vascularity and the conduction velocity of sciatic nerves in diabetic mice, partly via neural nitric oxide synthase/nitric oxide and phosphatidylinositol-3-kinase/Akt signaling pathways. ${ }^{19}$ However, because it is still unclear whether or not statins improve cardiac sympathetic neural dysfunction in DM, we investigated whether fluvastatin, which has a powerful antioxidative effect, ${ }^{21}$ could attenuate cardiac sympathetic neural dysfunction in DM and whether fluvastatin-induced attenuation of diabetic neural dysfunction is associated with a reduction in cardiac oxidative stress.

\section{Methods}

This study proceeded in accordance with the guidelines for animal experiments at the University of Toyama.

Received June 14, 2009; accepted December 2, 2009; released online January 26, 2010 Time for primary review: 18 days

Second Department of Internal Medicine, Graduate School of Medicine, University of Toyama, Toyama, Japan

Mailing address: Takashi Nozawa, MD, Second Department of Internal Medicine, Graduate School of Medicine, University of Toyama,

2630 Sugitani, Toyama 930-0194, Japan. E-mail: tnozawa@med.u-toyama.ac.jp

ISSN-1346-9843 doi:10.1253/circj.CJ-09-0402

All rights are reserved to the Japanese Circulation Society. For permissions, please e-mail: cj@j-circ.or.jp 


\begin{tabular}{lccc}
\hline Table 1. Body and Heart Weights and Hemodynamic Variables & & \\
& Non-DM & DM-VE & DM-FL \\
N & 7 & 6 & 7 \\
Body weight $(\mathrm{g})$ & $329 \pm 21$ & $265 \pm 36^{\star \star}$ & $252 \pm 33^{\star *}$ \\
Heart weight $(\mathrm{g})$ & $0.76 \pm 0.04$ & $0.62 \pm 0.09^{\star}$ & $0.61 \pm 0.08^{\star \star}$ \\
Heart/body weight ratio $\left(\times 10^{3}\right)$ & $2.31 \pm 0.10$ & $2.36 \pm 0.15$ & $2.42 \pm 0.11$ \\
Heart rate (beats/min) & $421 \pm 23$ & $353 \pm 28^{* *}$ & $380 \pm 50$ \\
SBP $(\mathrm{mmHg})$ & $118 \pm 17$ & $127 \pm 10$ & $122 \pm 13$ \\
\hline
\end{tabular}

${ }^{*} P<0.05,{ }^{* \star} P<0.01$ vs Non-DM.

Non-DM, non-diabetic rats; DM-VE, diabetic rats given vehicle; DM-FL, diabetic rats treated with fluvastatin; SBP, systolic blood pressure.

\begin{tabular}{|lccc|}
\hline Table 2. Blood Glucose and Plasma Lipid Levels & & & \\
N & Non-DM & DM-VE & DM-FL \\
Blood glucose $(\mathrm{mg} / \mathrm{dl})$ & 7 & 8 & 7 \\
TC $(\mathrm{mg} / \mathrm{dl})$ & $140 \pm 22$ & $441 \pm 56^{* *}$ & $410 \pm 109^{* *}$ \\
Triglyceride $(\mathrm{mg} / \mathrm{dl})$ & $64 \pm 15$ & $70 \pm 8$ & $75 \pm 13$ \\
\hline
\end{tabular}

${ }^{*} \mathrm{P}<0.05,{ }^{* \star} \mathrm{P}<0.01$ vs Non-DM.

$\mathrm{TC}$, total cholesterol. Other abbreviations seeb in Table 1.

\section{Experimental Animals}

DM was induced in male Wistar rats weighing $250-300 \mathrm{~g}$ by an intraperitoneal injection of $65 \mathrm{mg} / \mathrm{kg}$ of streptozotocin $(\mathrm{STZ}, \mathrm{n}=40)$. Non-DM control rats $(\mathrm{n}=14)$ were not injected with STZ. The rats with glucose levels $>250 \mathrm{mg} / \mathrm{dl}$ at 1 week after STZ injection were considered diabetic $(n=28)$ and used in the experiments. Two weeks later, fluvastatin $(10 \mathrm{mg}$. $\mathrm{kg}^{-1} \cdot$ day $^{-1}, \mathrm{n}=14$ ) or vehicle (DM controls: $0.1 \%$ carboxymethyl cellulose, $n=14$ ) was orally administered by gavage for 2 weeks. Standard rat chow and tap water were provided ad libitum throughout the study.

Systolic blood pressure and heart rate were measured using an indirect tail-cuff method (BP-98A, Softron) and lipid peroxides (LPO) in plasma were determined using a hemoglobin-methylene blue method that selectively detects the absolute quantity of $\mathrm{LOOH}$. Cardiac oxidative stress was then assessed as the levels of 8-isoprostaglandin $\mathrm{F}_{2 \alpha}\left(\mathrm{PGF}_{2 \alpha}\right)$ and nicotinamide-adenine dinucleotide phosphate (NADPH) oxidase subunit $\mathrm{p} 22^{\text {phox }}$ mRNA expression, and cardiac sympathetic neural function was assessed using ${ }^{131} \mathrm{I}-$ and ${ }^{125} \mathrm{I}-$ labeled MIBG.

\section{Radioactive MIBG Tracers}

FUJIFILM RI Pharma Co Ltd (Tokyo, Japan) prepared and supplied ${ }^{131} \mathrm{I}$ - and ${ }^{125}$ I-labeled MIBG at a radiochemical purity $>98 \%$, and specific activity of $30-70 \mathrm{GBq} / \mathrm{mmol}$.

\section{Cardiac MIBG Accumulation}

Dual-tracer autoradiography proceeded as described. ${ }^{22,23}$ Briefly, $0.37 \mathrm{MBq}$ of ${ }^{125} \mathrm{I}-\mathrm{MIBG}$ was injected via the external jugular vein under pentobarbital sodium anesthesia $(30 \mathrm{mg} / \mathrm{kg}$, ip). Two hours later, $1.85 \mathrm{MBq}$ of ${ }^{131} \mathrm{I}$-MIBG was intravenously injected and $30 \mathrm{~min}$ thereafter, the heart was removed and washed in cold saline. Specimens were frozen in isopentane, cooled in dry ice, embedded in methyl cellulose and cut into serial $20-\mu \mathrm{m}$ thick transverse sections. The uptake of ${ }^{131}$ I-MIBG was initially determined by autoradiographic exposure on imaging plates (BAS-UR, Fuji Film, Japan) for $6 \mathrm{~h}$. We allowed the ${ }^{131}$ I-MIBG to decay for 75 days and then determined ${ }^{125}$ I-MIBG uptake after autoradiographic expo- sure for 30 days. A preliminary study showed that cross-talk between the 2 tracers was negligible $(<2 \%)$ at the applied doses of ${ }^{131} \mathrm{I}$ and ${ }^{125} \mathrm{I}$.

We analyzed the autoradiographic images to determine cardiac MIBG uptake and distribution using a computerassisted imaging-processing system (BAS3000, Fuji Film), as described. ${ }^{22}$ Transverse sections of the left ventricle (LV) were divided into 4 segments at the level of the papillary muscles. Myocardial tracer accumulation in each region was normalized as a ratio (\%) of the administered dose per gram of heart tissue (\% $\%$ dose $/ \mathrm{g}$ ), using graded ${ }^{131} \mathrm{I}$ - and ${ }^{125} \mathrm{I}-$ labeled standards. The washout rates (WR) of MIBG in whole hearts and in individual segments were calculated as follows:

WR $(\%)=\left({ }^{131}\right.$ I accumulation $-{ }^{125}$ I accumulation $) \times 100 \div$

${ }^{131}$ I accumulation

\section{Cardiac PGF $2 \alpha$ Levels}

LV tissues were disrupted in a Polytron homogenizer with $50 \mathrm{mmol} / \mathrm{L} \mathrm{HCl}$ and the homogenate was centrifuged for $5 \mathrm{~min}$. The supernatant was extracted with ethyl acetate by centrifugation of $3,000 \mathrm{~g}$ for $5 \mathrm{~min}$ and the resulting organic layer was evaporated under a steam of nitrogen. The residue was dissolved in a mixture $(50 \mu \mathrm{l})$ of acetonitrile and ethanol, and then $1 \mathrm{mmol} / \mathrm{L} \mathrm{HCl}(2.5 \mathrm{ml})$ was added. Tissue extract was applied to Empore disk cartridges preconditioned with methanol and $1 \mathrm{mmol} / \mathrm{L} \mathrm{HCl}$. The cartridges were washed with $1 \mathrm{mmol} / \mathrm{L} \mathrm{HCl}$ followed by heptane. We eluted $\mathrm{PGF}_{2 \alpha}$ with ethyl acetate containing $1 \%$ methanol, and evaporated the eluate under a steam of nitrogen. The residue was dissolved in $0.05 \%$ formic acid and acetonitrile, and the $\mathrm{PGF}_{2} \alpha$ level was determined by high-performance liquid chromatographyelectrospray ionization-mass spectrometry (API $4000^{\mathrm{TM}} \mathrm{LC} /$ MS/MS, Applied Biosystems, Foster City, USA) ${ }^{24}$ The detection limit of $\mathrm{PGF}_{2 \alpha}$ was $0.1 \mathrm{ng} / \mathrm{g}$ tissue.

\section{NADPH Oxidase Subunit p22 phox mRNA Expression}

NADPH oxidase subunit $2^{2} 2^{\text {phox }}$ mRNA expression in the myocardium was evaluated by real-time reverse transcriptase-polymerase chain reaction (PCR). Total RNA was ex- 


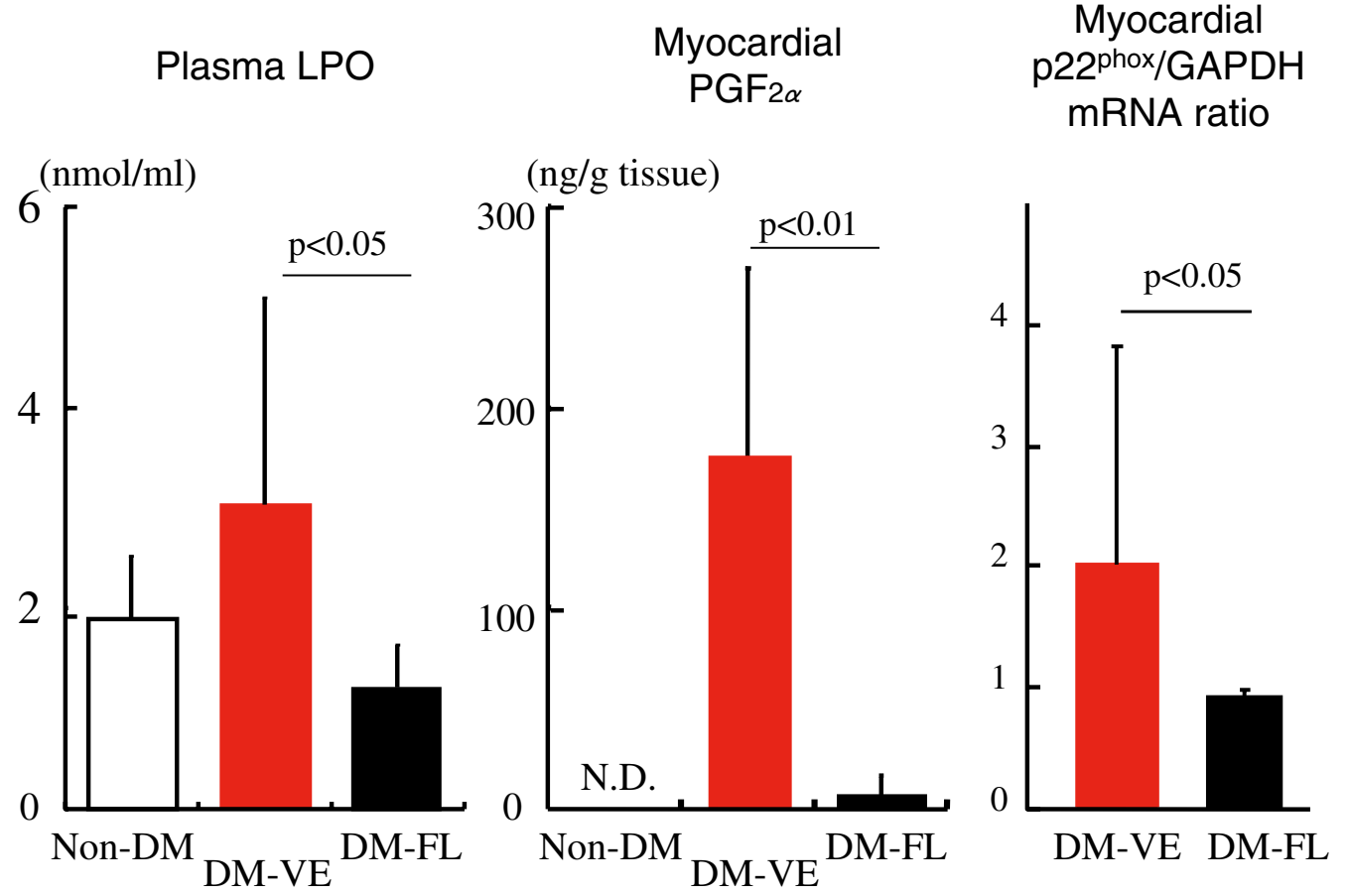

Figure 1. (Left \& Middle) Plasma levels of lipid peroxides (LPO) and myocardial 8-iso-prostaglandin $F_{2 \alpha}\left(P_{G F}\right.$ ) in non-diabetic rats (non-DM, $n=7$ and 5, respectively), diabetic rats given vehicle (DM-VE, $n=8$ and 5 , respectively), and diabetic rats treated with fluvastatin (DM-FL, $n=7$ and 5, respectively). (Right) Myocardial NADPH oxidase subunit p22 phox mRNA expression in DM$\operatorname{VE}(n=6)$ and $D M-F L(n=6)$ rats. Level of $P_{G F}$ is below detection limit in all non-DM and in 3 of 5 DM-FL rats. Means $\pm S D$.

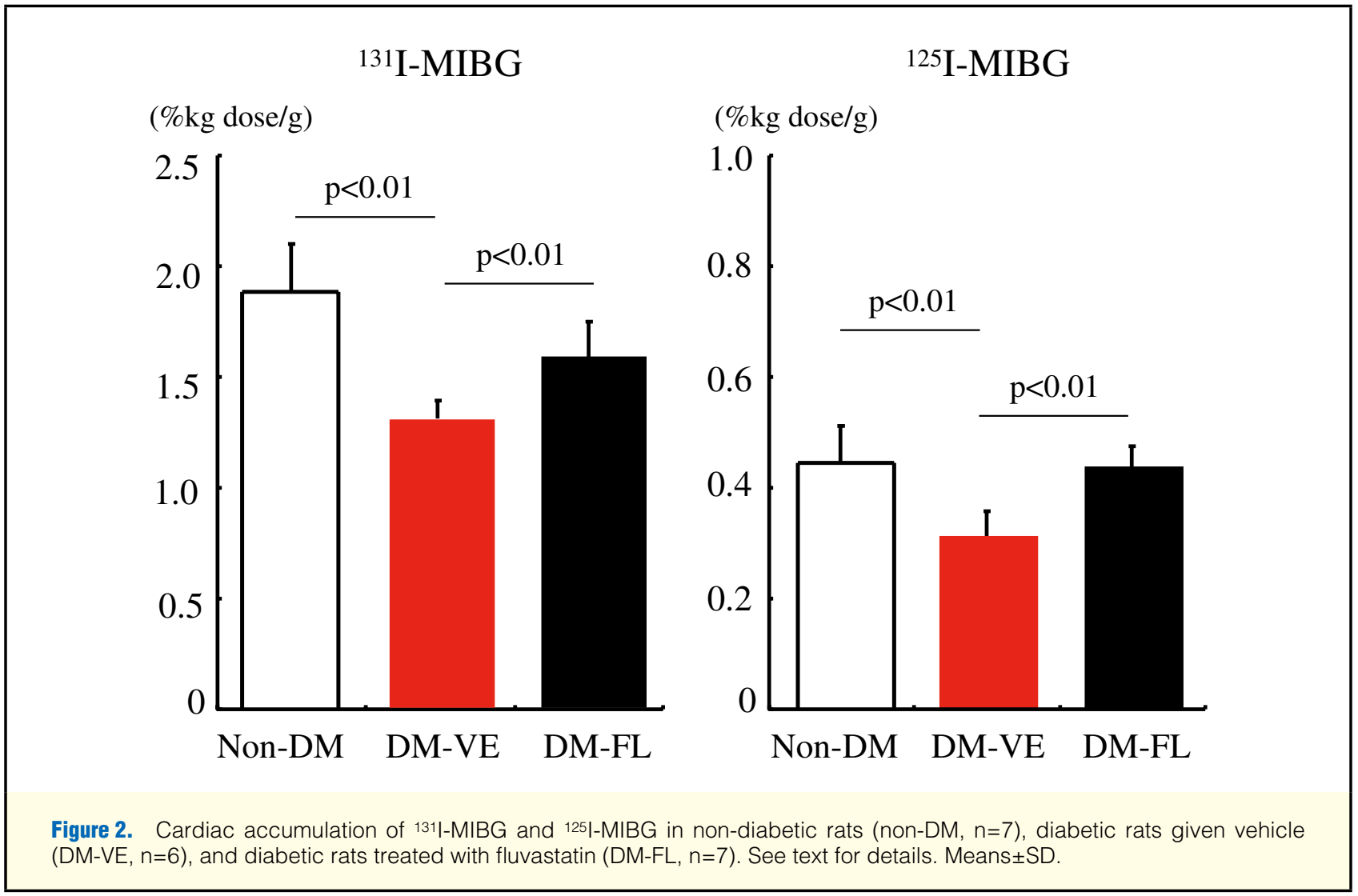



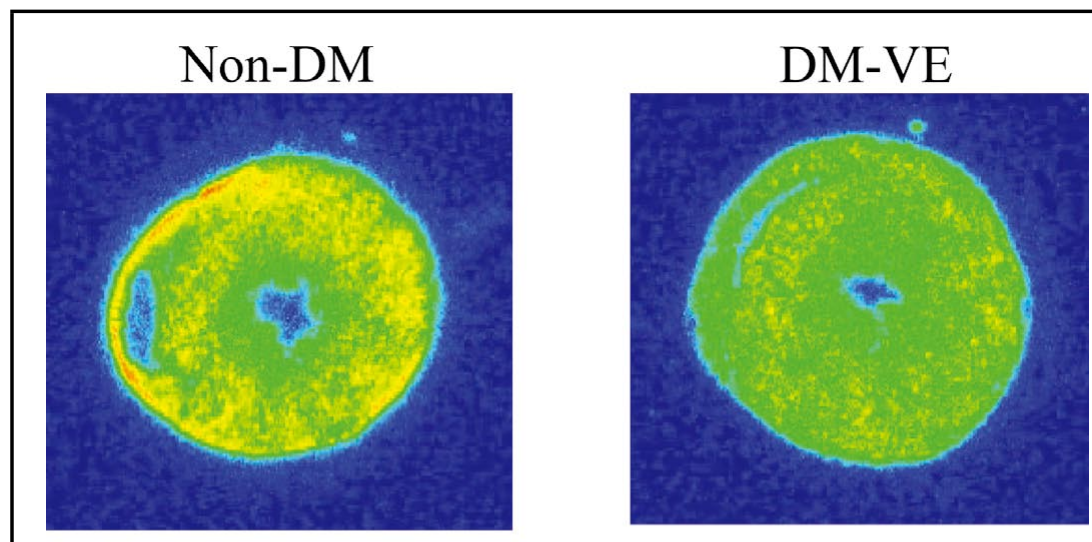

DM-FL
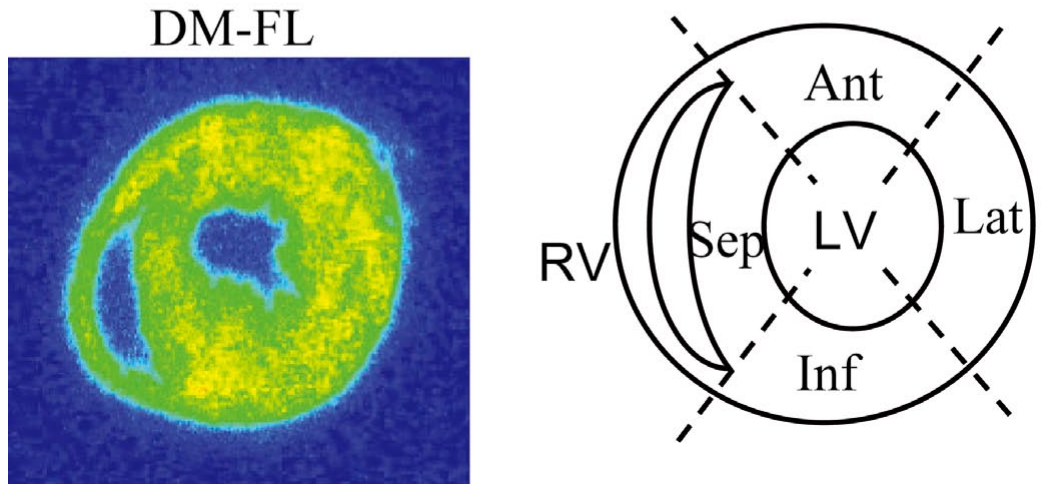

Figure 3. Examples of cardiac ${ }^{131} 1$-metaiodobenzylguanidine (MIBG) accumulation of non-diabetic (Non-DM), vehicletreated (DM-VE) and fluvastatin-treated diabetic (DM-FL) rats and schematic illustration of left ventricle (LV) (Right lower panel). MIBG accumulation is relatively homogeneous within LV in each rat. Schematic illustration shows LV divided into anterior (Ant), lateral (Lat), inferior (Inf) and septal (Sep) wall segments to evaluate regional MIBG accumulation.

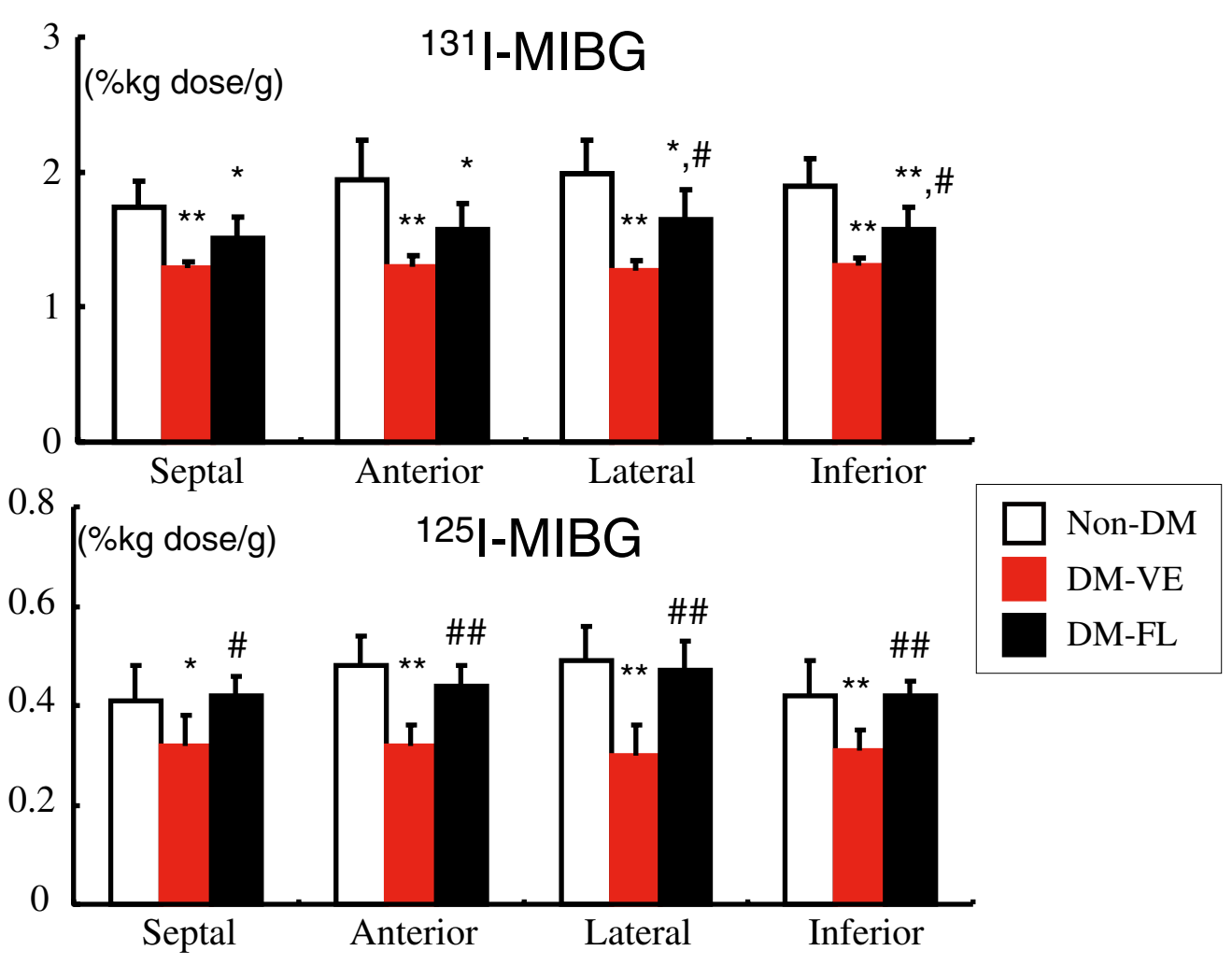

Figure 4. Cardiac regional accumulation of ${ }^{131}$ |- and ${ }^{125}$ I-metaiodobenzylguanidine (MIBG). ${ }^{*} P<0.05$ and ${ }^{* *} P<0.01$ vs non-diabetic rats (Non-DM), $P<0.05$ and ${ }^{\#} P<0.01$ vs diabetic rats given vehicle (DM-VE). DM-FL, diabetic rats treated with fluvastatin. Means \pm SD. 

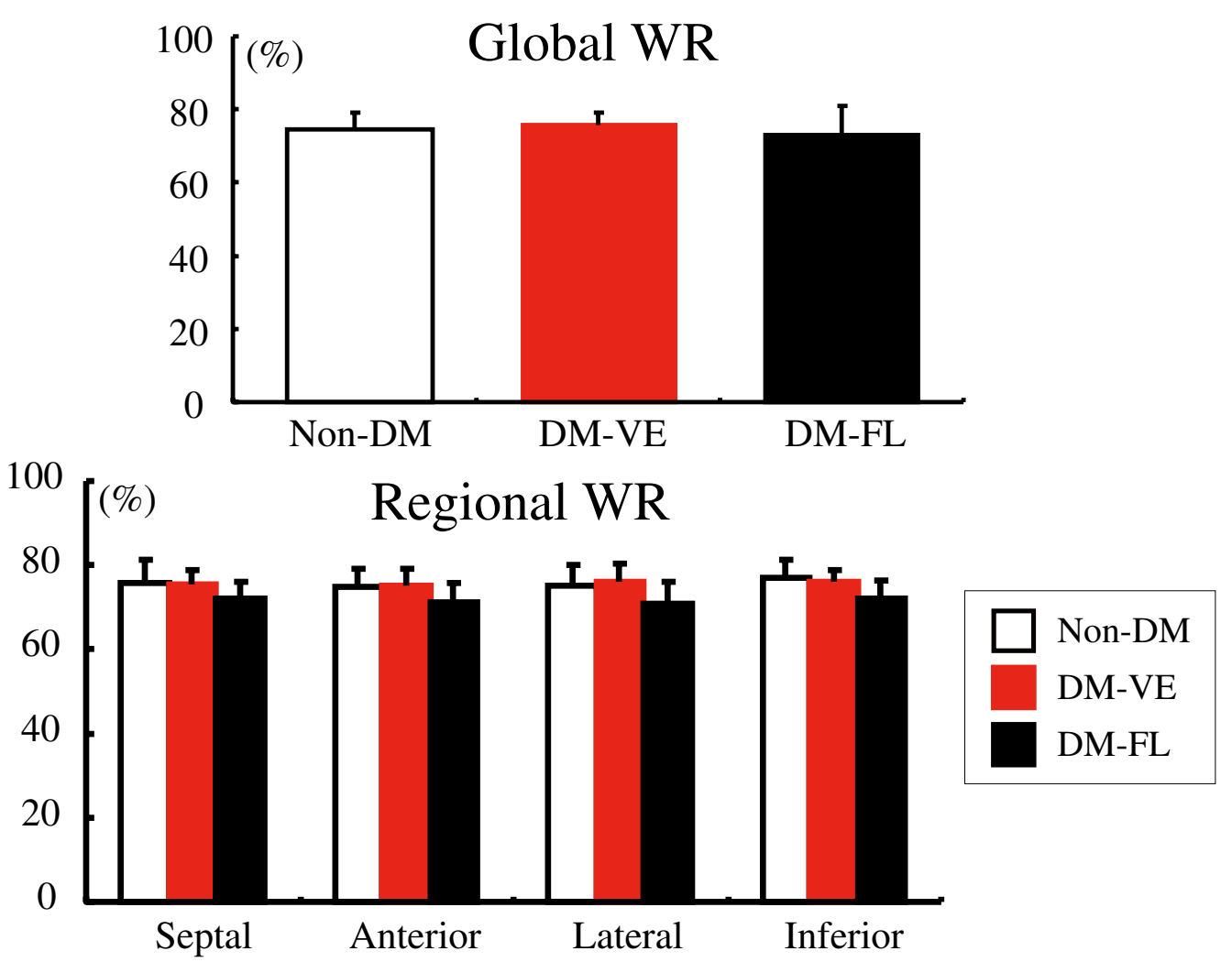

Figure 5. Global (Upper) and regional (Lower) washout rate (WR) of metaiodobenzylguanidine in the left ventricle. Non-DM, non-diabetic rats; DM-VE, diabetic rats given vehicle; DM-FL, diabetic rats treated with fluvastatin. Means $\pm S D$.

tracted from $100 \mathrm{mg}$ of LV tissue using Isogen (Nippon Gene, Japan), followed by digestion with DNase (Takara, Japan) to eliminate any contamination by genomic DNA. Total RNA samples were reverse transcribed with oligo (dT) primers by use of an RNA PCR kit (Takara ver 3.0, Japan). Quantitative real-time PCR analysis was performed with a sequence detector (Mx3000P, Stratagene) in a total volume of $20 \mu \mathrm{l}$ containing $1 \mu \mathrm{l}$ of cDNA, $10 \mu \mathrm{l}$ of reagent (Brilliant II Fast QPCR Master Mix, Stratagene), $8 \mu$ of diethylpyrocarbonatetreated water, and $1 \mu \mathrm{l}$ of primer and probe sets (Applied Biosystems) specific for cDNAs encoding NADPH subunits p22 $2^{\text {phox }}$ and glyceraldehyde-3-phsosphate dehydrogenase (GAPDH). PCR cycling programs were as follows: denaturation at $95^{\circ} \mathrm{C}$ for $1 \mathrm{~min}$, primer annealing at $40^{\circ} \mathrm{C}$ for $5 \mathrm{~s}$, and extension at $60^{\circ} \mathrm{C}$ for $20 \mathrm{~s}$ for 40 cycles. Gene expression of p22 ${ }^{\text {phox }}$ was normalized to that of GAPDH.

\section{Statistical Analysis}

Results are expressed as means \pm SD. Variables between 2 groups were compared using an unpaired t-test. Differences between groups were tested using a 1-way analysis of variance, followed by the Bonferroni test for multiple comparisons. A value of $\mathrm{P}<0.05$ was considered statistically significant.

\section{Results}

Both the body and the heart weighed less in rats with STZinduced DM than in the non-DM controls, but the ratio of heart to body weight did not differ between the 2 groups. Fluvastatin did not affect body and heart weights or the elevated blood glucose levels in the diabetic rats (Tables 1,2).

\section{Oxidative Stress}

Plasma levels of LPO tended to be higher in the DM rats than in non-DM controls, although the difference did not reach statistical significance. Fluvastatin significantly decreased LPO levels (Figure 1). Cardiac levels of $\mathrm{PGF}_{2} \alpha$ were below the detection limit $(<0.1 \mathrm{ng} / \mathrm{g} \mathrm{LV}$ tissue $)$ in the hearts of non-DM rats, but remarkably increased in all rats with STZinduced diabetes (Figure 1). Fluvastatin for 2 weeks obviously decreased the $\mathrm{PGF}_{2 \alpha}$ levels, which fell below the detection limit in 3 of 5 of the treated rats. Levels of NADPH oxidase subunit $\mathrm{p} 22^{\text {phox }} \mathrm{mRNA}$ expression were significantly reduced by fluvastatin (Figure 1).

\section{Cardiac MIBG Accumulation}

The accumulation of both ${ }^{131} \mathrm{I}$ - and ${ }^{125} \mathrm{I}-\mathrm{MIBG}$ in the LV was reduced in the DM rats compared with the non-DM group (Figure 2) and fluvastatin attenuated these decreases in the DM rats. Each LV was divided into 4 segments with regions of interest positioned on the LV anterior, septal, lateral and inferior walls at the level of the papillary muscle (Figure 3). Regional MIBG accumulation did not significantly differ in the non-DM rats, but the septal accumulation of ${ }^{131} \mathrm{I}-\mathrm{MIBG}$ and the septal and inferior accumulation of ${ }^{125}$ I-MIBG tended to be lower than in the corresponding anterior or lateral regions (Figure 4). The uptake of MIBG was significantly 
reduced in all segments of DM rat hearts. Fluvastatin restored the DM-induced reduction of both ${ }^{131} \mathrm{I}$ - and ${ }^{125} \mathrm{I}-\mathrm{MIBG}$ accumulation in these segments, but the increase in ${ }^{131} \mathrm{I}-\mathrm{MIBG}$ accumulation reached statistical significance only in the lateral and inferior regions.

Neither the induction of DM nor fluvastatin affected the WR of MIBG from the LV, and regional differences in WR among the non-DM, DM or fluvastatin-treated DM rats did not reach significance (Figure 5).

\section{Discussion}

In the present study, cardiac oxidative stress was markedly increased in rats with STZ-induced DM and fluvastatin treatment for 2 weeks significantly reduced the myocardial levels of $\mathrm{PGF}_{2 \alpha}$ and NADPH oxidase subunit p22 $2^{\text {phox }}$ mRNA expression. Fluvastatin also attenuated the decreased cardiac MIBG uptake in the DM rats. Because neither the induction of DM nor fluvastatin treatment affected the WR of MIBG from the LV, the reduced MIBG accumulation in the DM rats might have resulted from impaired neural norepinephrine uptake rather than from enhanced sympathetic activation. ${ }^{25}$ In our study, diabetic sympathetic neural dysfunction was homogeneous within the LV, but 2 studies identified a more obvious MIBG reduction in the inferior region of the diabetic heart. ${ }^{4,26}$ Fluvastatin-induced recovery of neural dysfunction was also homogeneous in the present study.

\section{Effects of Fluvastatin on Cardiac Oxidative Stress}

The F2 isoprostanes comprise a family of prostaglandin $\mathrm{F}_{2 \alpha}$ isomers that are formed in situ from the fatty acid backbone that is esterified in membrane phospholipids. In many previous studies, $\mathrm{PGF}_{2 \alpha}$, a major $\mathrm{F} 2$ isoprostane, has been used as a reliable marker of oxidative stress in various tissues. ${ }^{27-31}$

Others have shown that oxidative stress is increased in both type I and type II DM. ${ }^{32,33}$ Hyperglycemia induces oxidative stress through several pathways, ${ }^{10-13,34}$ including enhanced aldose reductase activity, ${ }^{10}$ increased advanced glycation end-products, ${ }^{11}$ altered protein kinase $\mathrm{C}$ activity ${ }^{12}$ and mitochondrial overproduction of superoxide. ${ }^{13}$ Matsushima et al found that glutathione peroxidase overexpression improved LV diastolic function, accompanied by the attenuation of myocyte hypertrophy, interstitial fibrosis and apoptosis, in mice with STZ-induced DM. ${ }^{35}$ Similarly, the attenuation of oxidative stress by overexpression of the antioxidant protein, metallothionein, or treatment with antioxidant $\mathrm{N}$-acetyl-cysteine improved myocyte function or fibrosis in the diabetic heart, ${ }^{36,37}$ and the increased urinary $\mathrm{PGF}_{2}$ levels seen in diabetic patients can be reduced by improving their metabolic control. ${ }^{32,38}$

The present study found that cardiac levels of $\mathrm{PGF}_{2 \alpha}$ in non-DM rats were below detection limits, but these levels increased in the DM rats, together with increased plasma levels of LPO, although the latter did not reach statistical significance. Long-term fluvastatin administration decreased both cardiac $\mathrm{PGF}_{2 \alpha}$ and plasma LPO levels to those found in the non-DM rats. The fluvastatin-induced reduction of myocardial oxidative stress was also confirmed by NADPH oxidase subunit $\mathrm{p} 22^{\text {phox }} \mathrm{mRNA}$ expression in the myocardium. Statins decrease free radical generation in the vascular wall and myocardium, ${ }^{39,40}$ and fluvastatin exerts potent antioxidant activities as a free radical scavenger, a property that is derived from its unique chemical structure. ${ }^{21,41}$ Thus, the present findings show that fluvastatin reduces cardiac oxidative stress in DM rats.

\section{Cardiac MIBG Accumulation}

Impaired cardiac norepinephrine uptake in diabetic hearts determined using MIBG or ${ }^{11} \mathrm{C}$-hydroxyephedrine is accompanied by decreases in cardiac norepinephrine transporter density $^{42}$ and nerve growth factor protein. ${ }^{43}$ The etiology of cardiac sympathetic nerve dysfunction in DM remains unclear, but the following mechanisms have been proposed: (1) degeneration of proteins critical to neural function by non-enzymatic glycosylation; ${ }^{44}$ (2) reduction of neurotrophic factors; ${ }^{45}$ (3) altered neural polyol metabolism; ${ }^{10}$ and (4) microvascular disease with impaired blood flow. ${ }^{46}$ However, increased oxidative stress in DM might be a major mechanism in the development of neuropathy. ${ }^{8,9}$ Oxidative stress can mediate the apoptosis of neurons and cause vascular impairment that leads to endoneural hypoxia and impaired neural function. Antioxidants, such as $\alpha$-lipoic acid, ${ }^{47}$ acetylL-carnitine ${ }^{48}$ and vitamins $\mathrm{E}$ and $\mathrm{C},{ }^{49}$ can ameliorate the nerve function deficit in diabetic neuropathy.

We found that 2-week treatment with fluvastatin attenuated the DM-induced reduction of cardiac MIBG accumulation in association with a reduction in cardiac oxidative stress. However, some investigators have reported increased cardiac norepinephrine uptake and increased cardiac sympathetic nerve activity in rats with STZ-induced DM. ${ }^{50,51} \mathrm{An}$ increase in cardiac sympathetic activity accelerates MIBG turnover at nerve terminals, resulting in decreased cardiac MIBG accumulation in delayed images. However, the present study found the same cardiac MIBG WR in the rats, regardless of fluvastatin administration. These findings suggest that the fluvastatin-induced improvement in cardiac MIBG accumulation did not result from suppressed sympathetic nerve activity, but rather from an improvement in neural norepinephrine uptake. Ii et al demonstrated that rosuvastatin improves sciatic nerve function in mice with type II DM via restored microcirculation and direct neurotrophic effects. ${ }^{19}$ Cameron et al reported that rosuvastatin improves sciatic and saphenous nerve conduction velocity in rats with STZ-induced DM. ${ }^{52}$ The present results suggest that improvement in diabetic sympathetic neuropathy induced by fluvastatin resulted from either suppressed neural oxidative stress or from an increase in endoneural blood flow through amelioration of oxidative stress-induced microvascular dysfunction in the diabetic heart.

Gill et al showed using single-photon emission computed tomography (SPECT) and MIBG images that heterogeneous human cardiac sympathetic innervation is accompanied by greater MIBG uptake in the anterolateral than in the inferoseptal region. ${ }^{53}$ This might arise partially from tissue attenuation or liver uptake of MIBG. However, animal experiments have shown a greater myocardial norepinephrine content in the LV anterolateral region, indicating increased sympathetic innervation, because norepinephrine is almost exclusively localized within adrenergic nerves. ${ }^{54}$ The present study found slightly greater MIBG uptake in the anterior and lateral regions than in the septal region in non-DM rats, although these differences did not reach statistical significance. Cardiac MIBG accumulation was reduced in all segments of the diabetic rat heart. However, a previous study ${ }^{26}$ found homogeneous cardiac MIBG accumulation in non-DM rats and a greater reduction in MIBG uptake in the inferior region of the diabetic rat heart. One study, however, found similar cardiac MIBG uptake between the anterior and inferior regions of the rat heart in a model of non-insulin dependent DM. ${ }^{42}$ We cannot plausibly explain these disparate results, including those of the present study. However, differences in the 
LV samples investigated, such as using the basal or apical side, might be a partial explanation, because sympathetic innervation is inhomogeneous within the heart. Regional LV innervation from the base to apex forms a gradient, being highest at the base and lowest at the apex. ${ }^{54}$

\section{Study Limitations}

Some limitations should be considered when interpreting the present results. Firstly, statins might exert favorable effects on diabetic neuropathy independently of their ability to lower cholesterol. We evaluated cardiac oxidative stress, but not other mechanisms, including improved endothelial function and antiinflammatory and antithrombotic processes. Diabetic neuropathy might arise from a combination of microvascular and neural deficits, ${ }^{8}$ and therefore, these mechanisms combined with reduced oxidative stress might contribute to the improved cardiac MIBG accumulation in DM rats. Moreover, whether or not statins other than fluvastatin have similar effects on diabetic sympathetic neuropathy remains unknown. Secondly, we did not measure myocardial blood flow, which would influence cardiac MIBG uptake. However, a previous study ${ }^{55}$ has shown that myocardial blood flow is not reduced in rats with STZ-induced DM, although coronary flow reserve might be impaired in the diabetic heart. ${ }^{56}$

\section{Conclusion}

Fluvastatin ameliorated cardiac sympathetic neuropathy in the diabetic rat heart in association with attenuation of increased cardiac oxidative stress. Autonomic neuropathy in diabetic patients is associated with high morbidity and mortality, so statins might help to prevent cardiovascular events and attenuate cardiac sympathetic neural dysfunction.

\section{Acknowledgments}

MIBG was generously supplied by FUJIFILM RI Pharma Co Ltd (Tokyo, Japan) and fluvastatin by Mitsubishi Tanabe Pharma Co Ltd (Osaka, Japan).

\section{References}

1. Ewing DJ, Cambell IW, Clarke BF. The natural history of diabetic autonomic neuropathy. Q J Med 1980; 49: 95-108.

2. O'Brien IA, McFadden JP, Corrall RJ. The influence of autonomic neuropathy on mortality in insulin-dependent diabetes. $Q \mathrm{~J} \mathrm{Med}$ 1991; 79: $495-502$.

3. Chen HS, Hwu CM, Kuo BI, Chiang SC, Kwok CF, Lee SH, et al. Abnormal cardiovascular reflex tests are predictors of mortality in Type 2 diabetes mellitus. Diabet Med 2001; 18: 268-273.

4. Hattori N, Tamaki N, Hayashi T, Masuda I, Kudoh T, Tateno M, et al. Regional abnormality of iodine-MIBG in diabetic hearts. $J$ Nucl Med 1996; 37: 1985-1990.

5. Kreiner G, Wolzt M, Fasching P, Leitha T, Edlmayer A, Korn A, et al. Myocardial $\mathrm{m}^{-123}$ I-iodobenzylguanidine scintigraphy for the assessment of adrenergic cardiac innervation in patients with IDDM. Diabetes 1995; 44: 543-549.

6. Langer A, Freeman MR, Josse RG, Armstrong PW. Metaiodobenzylguanidine imaging in diabetes mellitus: Assessment of cardiac sympathetic denervation and its relation to autonomic dysfunction and silent myocardial ischemia. J Am Coll Cardiol 1995; 25: 610 618.

7. Stevens MJ, Raffel DM, Allman KC, Dayanikli F, Ficaro E, Stanford T, et al. Cardiac sympathetic dysinnervation in diabetes: Implications for enhanced cardiovascular risk. Circulation 1998; 98: $961-968$.

8. Vincent AM, Russell JW, Low P, Feldman EL. Oxidative stress in the pathogenesis of diabetic neuropathy. Endocr Rev 2004; 25: $612-628$.

9. Pop-Busui R, Sima A, Stevens M. Diabetic neuropathy and oxidative stress. Diabetes Metab Res Rev 2006; 22: 257-273.

10. Yagihashi S, Yamagishi S, Wada R, Baba M, Hohman TC, Yabe-
Nishimura C, et al. Neuropathy in diabetic mice overexpressing human aldose reductase and effects of aldose reductase inhibitor. Brain 2001; 124: $2448-2458$

11. Brownlee M, Cerami A, Viassara H. Advanced products of nonenzymatic glycosylation and the pathogenesis of diabetic vascular disease. Diabetes Metab Rev 1988; 4: 437-451.

12. Craven PA, DeRubertis FR. Protein kinase $\mathrm{C}$ is activated in glomeruli from streptozotocin diabetic rats: Possible mediation by glucose. J Clin Invest 1989; 83: 1667-1675.

13. Brownlee M. A radical explanation for glucose-induced $\beta$ cell dysfunction. J Clin Invest 2003; 112: 1788-1790.

14. Heart Protection Study Collaborative Group. MRC/BHF Heart Protection Study of cholesterol-lowering with simvastatin in 5963 people with diabetes: A randomised placebo-controlled trial. Lancet 2003; 361: 2005-2016.

15. Sowers JR. Effects of statins on the vasculature: Implications for aggressive lipid management in the cardiovascular metabolic syndrome. Am J Cardiol 2003; 91: 14B-22B.

16. Rikitake Y, Hirata K. Inhibition of Rho A or Rac1? Mechanism of cholesterol-independent beneficial effects of statins. Circ J 2009; 73: $231-232$.

17. Zhang M, Zhou SH, Li XP, Shen XQ, Fang ZF, Liu QM, et al. Atorvastatin downregulates BMP-2 expression induced by oxidized low-density lipoprotein in human umbilical vein endothelium cells. Circ J 2008; 72: 807-812.

18. Nangle MR, Cotter MA, Cameron NE. Effects of rosuvastatin on nitric oxide-dependent function in aorta and corpus cavernosum of diabetic mice: Relationship to cholesterol biosynthesis pathway inhibition and lipid lowering. Diabetes 2003; 52: 2396-2402.

19. Ii M, Nishimura H, Kusano K, Qin G, Yoon Y, Wecker A, et al. Neural nitric oxide synthase mediates statin-induced restoration of vasa nervorum and reversal of diabetic neuropathy. Circulation 2005; 112: $93-102$.

20. Fried LF, Forrest KYZ, Ellis D, Chang Y, Silvers N, Orchard TJ. Lipid modulation in insulin-dependent diabetes mellitus: Effect on microvascular outcomes. J Diabetes Complicat 2001; 15: 113-119.

21. Suzumura K, Tanaka K, Yasuhara M, Narita H. Inhibitory effects of fluvastatin and its metabolites on hydrogen peroxide-induced oxidative destruction of hemin and low-density lipoprotein. Biol Pharm Bull 2000; 23: 873-878.

22. Nozawa T, Igawa A, Yoshida N, Maeda M, Inoue M, Yamamura Y, et al. Dual-tracer assessment of coupling between cardiac sympathetic neuronal function and downregulation of $\beta$-receptors during development of hypertensive heart failure of rats. Circulation 1998; 97: $2359-2367$.

23. Kato B, Nozawa T, Igarashi N, Nonomura M, Fujii N, Igawa A, et al. Discrepant recovery course of sympathetic neuronal function and $\beta$-adrenoceptors in rat hearts after reperfusion following transient ischemia. J Nucl Med 2004; 45: 1074-1080.

24. Ohashi N, Yoshikawa M. Rapid and sensitive quantification of 8 -isoprostaglandin $\mathrm{F}_{2 \alpha}$ in human plasma and urine by lipid chromatography-electrospray ionization mass spectrometry. J Chromatogr $B$ 2000; 746: $17-24$.

25. Imamura Y, Ando H, Mitsuoka W, Egashira S, Masaki H, Ashihara $\mathrm{T}$, et al. Iodine-123 metaiodobenzylguanidine images reflect intense myocardial adrenergic nervous activity in congestive heart failure independent of underlying cause. J Am Coll Cardiol 1995; 26: $1594-1599$.

26. Kiyono Y, Iida Y, Kawashima H, Tamaki N, Nishimura H, Saji $\mathrm{H}$. Regional alterations of myocardial norepinephrine transporter density in streptozotocin-induced diabetic rats: Implications for heterogeneous cardiac accumulation of MIBG in diabetes. $J$ Nucl Med 2001; 28: 894-899.

27. Singh B, Mense SM, Remotti F, Liu R, Bhat HK. Antioxidant butylated hydroxyanisole inhibits estrogen-induced breast carcinogenesis in female ACI rats. J Biochem Mol Toxicol 2009; 23: $202-211$.

28. Potenza MA, Gagliardi S, Benedictis L, Zigrino A, Tiravanti E, Colantuono G, et al. Treatment of spontaneously hypertensive rats with rosiglitazone ameliorates cardiovascular pathophysiology via antioxidant mechanism in the vasculature. Am J Physiol Endcrinol Metab 2009; 297: E685-E694.

29. Mallat Z, Nakamura T, Ohan J, Leseche G, Tedgui A, Maclouf J, et al. The relationship of hydroxyeicosatetraenoic acids and $\mathrm{F}_{2}-$ isoprastanes to plaque instability in human carotid atherosclerosis. J Clin Invest 1999; 103: 421-427.

30. Pratico D, MY Lee V, Trojanowski JQ, Rokach J, Fitzgerald GA. Increased $F_{2}$-isoprostanes in Alzheimer's disease: Evidence for enhanced lipid peroxidation in vivo. FASEB $J$ 1998; 12: $1777-$ 1783. 
31. Morrow JD, Awad JA, Kato T, Takahashi K, Badr KF, Roberts II $\mathrm{LJ}$, et al. Formation of novel non-cyclooxygenase-derived prostanoids ( $\mathrm{F}_{2}$-isoprostanes) in carbon tetrachloride hepatotoxicity. J Clin Invest 1992; 90: 2502-2507.

32. Davi G, Ciabattoni G, Consoli A, Mezzetti A, Falco A, Santarone $\mathrm{S}$, et al. In vivo formation of 8-iso-prostaglandin $\mathrm{F}_{2} \alpha$ and platelet activation in diabetes mellitus: Effects of improved metabolic control and vitamin E supplementation. Circulation 1999; 99: 224 229.

33. Crespo MJ, Zalacain J, Dunbar DC, Arocho L. Cardiac oxidative stress is elevated at the onset of dilated cardiomyopathy in streptozotocin-diabetic rats. J Cardiovasc Pharmacol Ther 2008; 13: $64-71$

34. Takei Y, Tomiyama H, Tanaka N, Yamashina A. Close relationship between sympathetic activation and coronary microvascular dysfunction during acute hyperglycemia in subjects with atherosclerotic risk factors. Circ J 2007; 71: 202-206.

35. Matsushima S, Kinugawa S, Ide T, Matsusaka H, Inoue M, Ohta Y, et al. Overexpression of glutathione peroxidase attenuates myocardial remodeling and preserves diastolic function in diabetic heart. Am J Physiol Heart Circ Physiol 2006; 291: H2237-H2245.

36. Ye G, Metreveli NS, Ren J, Epstein PN. Metallothionein prevents diabetes-induced deficits in cardiomyocytes by inhibiting reactive oxygen species protection. Diabetes 2003; 52: 777-783.

37. Fiordaliso F, Bianchi R, Staszewsky L, Cuccovillo I, Doni M, Laragione T, et al. Antioxidant treatment attenuates hyperglycemiainduced cardiomyocyte death in rats. J Mol Cell Cardiol 2004; 37: 959-968.

38. De Cristofaro R, Rocca B, Vitacolonna E, Falco A, Marchesani P, Ciabattoni $\mathrm{G}$, et al. Lipid and protein oxidation contribute to a prothrombotic state in patients with type 2 diabetes mellitus. $J$ Thromb Haemost 2003; 1: 250-256.

39. Erös B, Snipes JA, Tulbert CD, Katakam P, Miller AW, Busija DW. Rosuvastatin improves cerebrovascular function in Zuker obese rats by inhibiting $\mathrm{NAD}(\mathrm{P}) \mathrm{H}$ oxidase-dependent superoxide production. Am J Physiol Heart Circ Physiol 2006; 290: H1264-H1270.

40. Takemoto M, Node K, Nakagami H, Liao Y, Grimm M, Takemoto $\mathrm{Y}$, et al. Statins as antioxidant therapy for preventing cardiac myocyte hypertrophy. J Clin Invest 2001; 108: 1429-1437.

41. Katoh M, Kurosawa Y, Tanaka K, Watanabe A, Doi H, Narita H Fluvastatin inhibits $\mathrm{O}_{2}{ }^{-}$and ICAM-1 levels in a rat model with aortic remodeling induced by pressure overload. Am J Physiol Heart Circ Physiol 2001; 281: H655-H660.

42. Kiyono Y, Iida Y, Kawashima H, Ogawa M, Tamaki N, Nishimura $\mathrm{H}$, et al. Norepinephrine transporter density as a causative factor in alterations in MIBG myocardial uptake in NIDDM model rats. Eur J Nucl Med 2002; 29: 999-1005.

43. Schmid H, Forman LA, Cao X, Sherman PS, Stevens MJ. Heterogeneous cardiac sympathetic denervation and decreased myocar- dial nerve growth factor in streptozotocin-induced diabetic rats. Diabetes 1999; 48: 603-608.

44. Cullum NA, Mahon J, Stringer K, McLean WG. Glycation of rat sciatic nerve tubulin in experimental diabetes mellitus. Diabetologia 1991; 34: 387-389.

45. Tomlinson DR, Fernyhough P, Diemel LT. Role of neurotrophins in diabetic neuropathy and treatment with nerve growth factors. Diabetes 1997; 46(Suppl 2): S43-S49.

46. Oltman CL, Coppey LJ, Gellett JS, Davidson EP, Lund DD, Yorek MA. Progression of vascular and neural dysfunction in sciatic nerves of Zucker diabetic fatty and Zucker rats. Am J Physiol Endocrinol Metab 2005; 289: E113-E122.

47. Cameron NE, Cotter MA, Horrobin DH, Tritschler HJ. Effects of alpha-lipoic acid on neurovascular function in diabetic rats: Interaction with essential fatty acids. Diabetologia 1998; 41: 390-399.

48. Sima AAF, Calvani M, Mehra M, Amato A, for the Acetyl-Carnitine Study Group. Acetyl-L-carnitine improves pain, nerve regeneration, and vibratory perception in patients with chronic diabetic neuropathy. Diabetes Care 2005; 28: 96-101.

49. Baydas G, Nedzvetskii VS, Tuzcu M, Yasar A, Kirichenko SV. Increase of glial fibrillary acidic proteins and S-100B in hippocampus and cortex of diabetic rats: Effects of vitamin E. Eur J Pharmacol 2003; 21: 67-71.

50. Ganguly PK, Dhalla KS, Innes IR, Beamish RE, Dhalla NS. Altered norepinephrine turnover and metabolism in diabetic cardiomyopathy. Circ Res 1986; 59: 684-693.

51. Ganguly PK, Beamish RE, Dhalla KS, Innes IR, Dhalla NS. Norepinephrine storage, distribution, and release in diabetic cardiomyopathy. Am J Physiol Endocrinol Metab 1987; 252: E734-E739.

52. Cameron N, Cotter M, Inkster M, Nangle M. Looking to the future: Diabetic neuropathy and effects of rosuvastatin on neurovascular function in diabetic models. Diabetes Res Clin Pract 2003; 61: S35-S39.

53. Gill JS, Hunter GJ, Gane G, Camm AJ. Heterogeneity of the human myocardial sympathetic innervation: In vivo demonstration by iodine 123-labeled metaiodobenzylguanidine scintigraphy. Am Heart J 1993; 126: 390-398.

54. Pierpont GL, DeMaster EG, Cohn JN. Regional differences in adrenergic function within the left ventricle. Am J Physiol Heart Circ Physiol 1984; 246: H824-H829.

55. Iltis I, Kober F, Dalmasso C, Cozzone PJ, Bernard M. Noninvasive characterization of myocardial blood flow in diabetic, hypertensive and diabetic-hypertensive rats using spin-labeling MRI. Microcirculation 2005; 12: 607-614.

56. Pop-Busui R, Kirkwood I, Schmid H, Marinescu V, Schroeder J, Larkin D, et al. Sympathetic dysfunction in type 1 diabetes: Association with impaired myocardial blood flow reserve and diastolic dysfunction. J Am Coll Cardiol 2004; 44: 2368-2374. 